To appear in Proceedings of IGARSS '98, Seattle, WA July 6-10, 1998.

\title{
Analysis of HYDICE Data for Information Fusion in Cartographic Feature Extraction*
}

\author{
Stephen J. Ford \\ Jefferey A. Shufelt \\ J. Chris McGlone \\ Steven Douglas Cochran \\ Wilson A. Harvey \\ David M. McKeown, Jr. \\ Digital Mapping Laboratory \\ Computer Science Department \\ Carnegie Mellon University \\ 5000 Forbes Avenue \\ Pittsburgh, PA 15213-3891 \\ Telephone: +1 (412)-268-7552 Facsimile: +1 (412)-268-5576 \\ EMail: $\{$ sford,jcm,sdc,js,wah,dmm $\} @$ cs.cmu.edu
}

\begin{abstract}
Late in 1995 we organized a hyperspectral data acquisition using the Naval Research Laboratory's Hyperspectral Digital Imagery Collection Experiment sensor system over Fort Hood, Texas. This acquisition resulted in hyperspectral data with a nominal 2 meter ground sample distance collected with 210 spectral samples per pixel.

This paper describes current quantitative classification results for man-made and natural materials using 14 surface material classes over selected test areas within Fort Hood. We discuss the issues encountered in radiometric effects due to changing solar illumination and atmospheric conditions during the acquisition. We also describe our approach to image registration and geopositioning, using a full photogrammetric block adjustment solution.
\end{abstract}

\section{INTRODUCTION}

A major focus of our research over the last five years has been the utilization of multispectral imagery to generate surface material maps. Surface material information is of interest to us both for cartographic feature extraction (CFE), to generate feature hypotheses or to refine features generated by other CFE systems, and for visual simulation, to select realistic visual textures.

Some of our previous research in fusion has involved the combination of surface material information with highresolution stereo elevation data to produce more refined surface material maps and to aid in distinguishing man-made structures within the scene [1], [2]. We are currently studying the combination of surface material maps with automatically extracted buildings and roads for editing and verification.

\footnotetext{
*The research reported in this paper was supported by the Defense Advanced Research Projects Agency (DARPA/ISO/SE) and the U.S. Army Topographic Engineering Center under Contract DACA76-92-C-0036. The views and conclusions contained in this document are those of the authors and should not be interpreted as representing the official policies, either expressed or implied, of the U.S. Army Topographic Engineering Center, the Defense Advanced Research Projects Agency, or of the United States Government.
}

One important limitation in this work has been the limited spatial resolution (8-20 meters) of available multispectral imagery. Since we require the precise delineation of object boundaries and the attribution of surface materials for small regions, such as those found within urban areas, we typically work with panchromatic imagery with ground sample distances (GSD) of 0.3 to 1.0 meters. Combining classification results from multispectral imagery with much coarser spatial resolution imposes limitations on the utility of the fusion.

In order to obtain data with higher spatial and spectral resolution we organized a hyperspectral data acquisition using the Naval Research Laboratory's (NRL) Hyperspectral Digital Imagery Collection Experiment (HYDICE) sensor. This acquisition, in October, 1995, resulted in hyperspectral data with a nominal 2 meter GSD collected with 210 spectral samples per pixel. The acquisition covered 56 square kilometers over Fort Hood, Texas, a site that has been used extensively in the Defense Advanced Research Projects Agency (DARPA) Image Understanding community to support experiments in semiautomated and automated CFE.

This paper describes current quantitative classification results for man-made and natural materials using 14 surface material classes over selected test areas within Fort Hood. Our performance evaluation methodology for surface material classification was previously presented in [3] for Daedalus Airborne Thematic Mapper (ATM) imagery over Washington, DC; a similar evaluation procedure is employed with the Fort Hood HYDICE imagery. We discuss the issues encountered in radiometric effects due to changing solar illumination and atmospheric conditions during the acquisition, which must be accounted for in order to support comparison of surface material properties across multiple HYDICE flightlines. Finally, accurate geopositioning of HYDICE imagery is crucial in performing fusion of surface material information with stereo and monocular cues. We describe our image registration procedure, based on a full photogrammetric block adjustment of the HYDICE and additional frame imagery. 


\section{GEOMETRIC AND RADIOMETRIC ISSUES}

Two major problems, radiometry and geopositioning, must be addressed in order to effectively utilize the HYDICE imagery in conjunction with other types of images for CFE.

The radiometric problems arise from the effects of changing atmospheric conditions and solar illumination on the groundreflected spectral radiance collected by the hyperspectral sensor. In order to compare surface material properties between flightlines and to utilize spectral field measurements of surface materials for spectral analysis, atmospheric corrections are applied to convert HYDICE radiance imagery to apparent reflectance.

Geometric issues are due to the dynamic nature of the image acquisition process and to the weak geometric configuration of the sensor, as discussed in "Registration of HYDICE Imagery", below. For large-scale mapping or more standard remote sensing applications, accurate positioning has been less important. However, to meet our goals of fusing surface material regions with features derived from our road and building extraction systems for high-resolution site modeling, extremely accurate absolute geopositioning and also relative registration between images must be established.

\section{DATA ACQUISITION}

The collection of data at Fort Hood included both airborne imagery and ground truth measurements. The image acquisition included hyperspectral imagery collected by the HYDICE sensor system and natural color film shot by a KS-87 frame reconnaissance camera. The spectral range of the HYDICE sensor extends from the visible to the short wave infrared (400-2500 nanometers) regions, divided into 210 channels with nominal 10 nanometer bandwidths.

Nine HYDICE flightlines, each 640 meters wide (crosstrack) and 12.6 kilometer long (along-track), were flown over Fort Hood's motor pool, barrack and main complex areas. After each flightline, the HYDICE sensor was flown over and imaged a six-step $(2,4,8,16,32$ and 64 percent) gray scale panel, providing in-scene radiometric calibration measurements for each flightline. Prior to the start of the HYDICE flight collection, several ground spectral measurements were made for each gray level panel in an attempt to characterize its mean spectral reflectance curve. A more detailed description of the HYDICE sensor system, Fort Hood image acquisition and ground truthing activities can be found in [4].

\section{REGISTRATION OF HYDICE IMAGERY}

Precise image registration is an absolute requirement for the fusion of information from multiple images. Registration of the HYDICE imagery presents special problems, requiring modeling of the linear pushbroom sensor geometry and also modeling the motion of the platform during the dynamic imaging process.
The perspective geometry of a linear pushbroom sensor is modeled as a one-dimensional frame sensor. This inherently weak geometry leads to high correlations between the orientation and position parameters in a resection solution, making their determination difficult. Since the platform is moving while the imagery is acquired, each line has a different position and orientation. The platform model must therefore describe the sensor position and orientation as a function of the image line number.

A common registration approach is to use navigational sensors such as GPS (Global Positioning System) and INS (Inertial Navigation System) to determine the position and orientation of the sensor at intervals along the flight path. Depending on the types of navigation sensors and their accuracies, this may not provide sufficient registration accuracy for fusion purposes. In any event, this was not an option for our data set due to navigation sensor malfunctions and system integration problems. We were also adversely impacted by acquisition conditions; due to time constraints, the Fort Hood flights were made during turbulent atmospheric conditions which adversely affected the image geometry.

In order to obtain the best possible registration, given our data set and its lack of navigation information, we are using a simultaneous block adjustment of multiple images and image types. Control information includes tie and control points and also geometric information (straight lines) within the scene. The use of straight line geometric constraints in the adjustment adds important geometric strength to the solution.

Three sets of imagery are being used in this adjustment:

- The HYDICE imagery, collected in nine sidelapping flight lines with a GSD of 2 meters.

- Color frame imagery, collected on the HYDICE flights by an uncalibrated KS-87 reconnaissance camera and scanned at 1 meter GSD.

- Nadir and oblique frame mapping camera imagery, scanned at a 0.3 meter GSD for the vertical images. These images were originally flown and triangulated for the DARPA Research And Development in Image Understanding Systems (RADIUS) program.

We have completed a sub-block adjustment consisting of 8 HYDICE, $10 \mathrm{KS}-87$, and 22 RADIUS images covering several test areas, with registration accuracies for the HYDICE images in the range of 5-10 meters (2-5 pixels). Current work is directed toward replacing the cubic polynomial platform model with a spline model which allows more degrees of freedom in describing the platform motion.

\section{ANALYSIS OF HYDICE IMAGERY}

Due to the volume of image data collected by the HYDICE hyperspectral sensor, these classification experiments used a reduced image dataset. To build on our previous experience with 


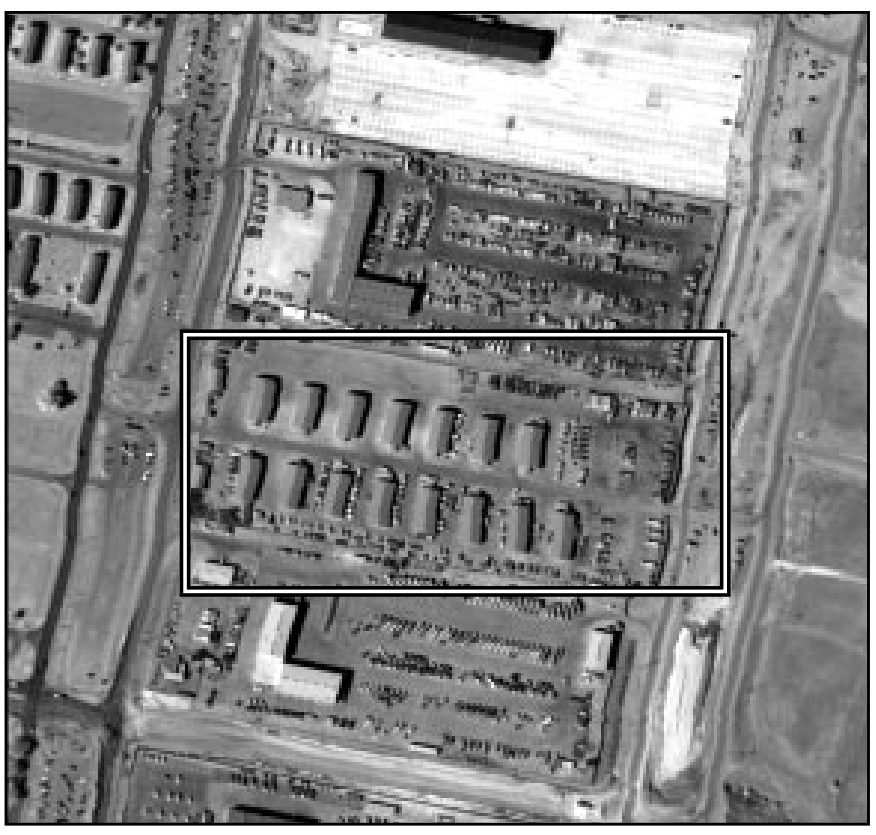

(a) RADT9 test area from Flightline 4.

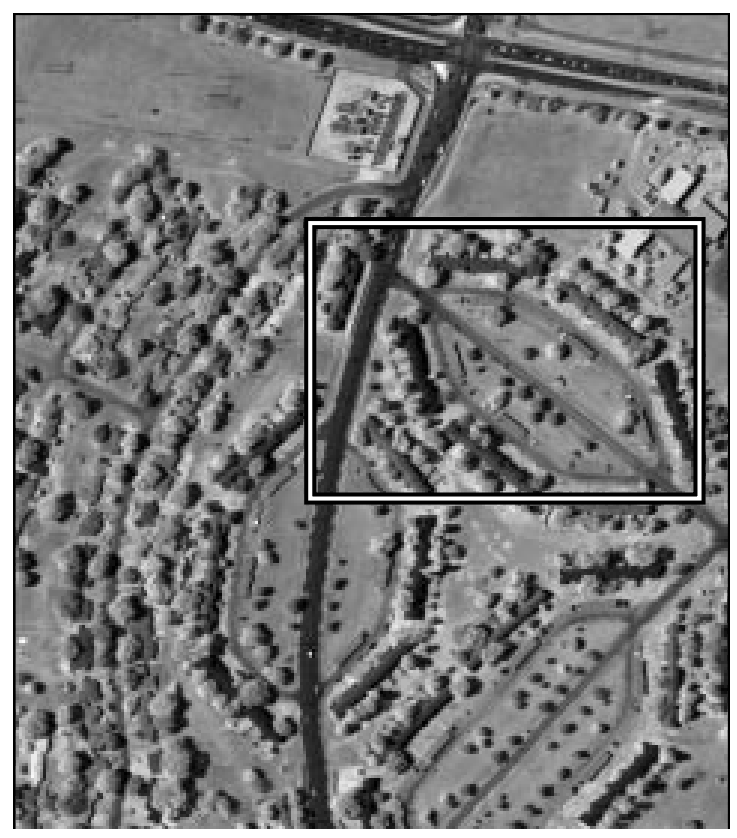

(b) CHAFFEE test area from Flightline 7.

Fig. 1: Simulated Daedalus ATM near infrared imagery (Band 7) of classification test areas.

TABLE I: Daedalus ATM spectral bandpasses.

\begin{tabular}{||c|c|c|c||}
\hline $\begin{array}{c}\text { Band } \\
\text { Number }\end{array}$ & $\begin{array}{c}\text { Bandpass } \\
\text { (micrometer) }\end{array}$ & $\begin{array}{c}\text { Band } \\
\text { Number }\end{array}$ & $\begin{array}{c}\text { Bandpass } \\
\text { (micrometer) }\end{array}$ \\
\hline \hline 1 & $0.420-0.450$ & 6 & $0.690-0.750$ \\
2 & $0.450-0.520$ & 7 & $0.760-0.900$ \\
3 & $0.520-0.600$ & 8 & $0.910-1.050$ \\
4 & $0.600-0.620$ & 9 & $1.550-1.750$ \\
5 & $0.630-0.690$ & 10 & $2.080-2.350$ \\
\hline
\end{tabular}

Daedalus ATM imagery, we simulated Daedalus ATM imagery by averaging the HYDICE imagery bands contained within the solar reflective bandpasses of the Daedalus ATM scanner (Table I).

Fig. 1 shows the two test areas used in the surface material classification experiments. The test areas' scene composition include motor pool/barracks (Fig. 1(a)) and residential (Fig. 1(b)) landscapes. Differing percentages and types of natural and man-made materials are present in each of these test areas.

The test areas are from Flightlines 4 and 7, which have acquisition time differences of 60 minutes. Downwelling radiometric conditions between these flightlines changed significantly, as recorded by ground spectral radiance measurements during the overflights. To minimize the effects of changing solar illumination and atmospheric conditions between flightlines, the simulated Daedalus ATM imagery was converted to apparent reflectance by using the gray scale panel imagery and spectral reflectance measurements to calculate band gain and offset coefficients for each flightline.
Manually-selected training sets for the materials listed in the "Fine Surface Material" column of Table II were compiled from an earlier section of Flightline 4. A Gaussian Maximum Likelihood (GML) classification was performed using the 10 simulated Daedalus ATM bands and selected training sets. Fig. 2 shows a surface material subsection map from the resulting classification. These subsection maps correspond to the outlined regions shown in Fig. 1 for the respective test areas.

The resulting surface material maps were evaluated against manually-generated surface material ground truths for each test area. Classification accuracies are $57.9 \%$ for RADT 9 and $60.4 \%$ for CHAFFEE. From Table III, almost $20 \%$ of RADT9's classification error is associated with confusion among concrete, asphalt, soil and gravel. Looking at Fig. 2(a), there is breakup of the parking lot into asphalt and concrete sections probably influenced by surface weathering and vehicular traffic. Also, the barrack roofs fluctuate in surface material classification due to illumination changes influenced by building roof structure. Reviewing Table IV, approximately $12 \%$ of CHAFFEE's classification error belongs to shadow, deciduous tree and grass confusions. From Fig. 1(b) and Fig. 2(f), trees and grass dominate the scene content of this test area. Some of this reported error is inherent in the ground truth due to the complexity of attempting to segment out regions of overlapping tree shadows and canopies surrounded by grass.

We are also interested in coarse surface material classification, whereby the fine surface material classes are grouped into more general categories as listed in Table II. This type of broad categorization is useful in identifying areas containing man- 


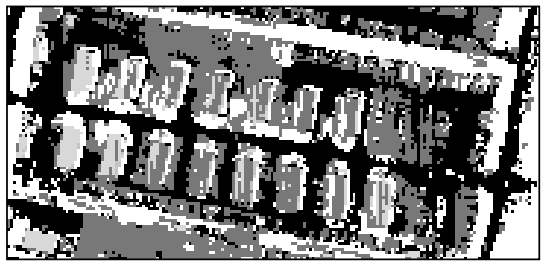

(a) RADT9 man-made surface/roofing.

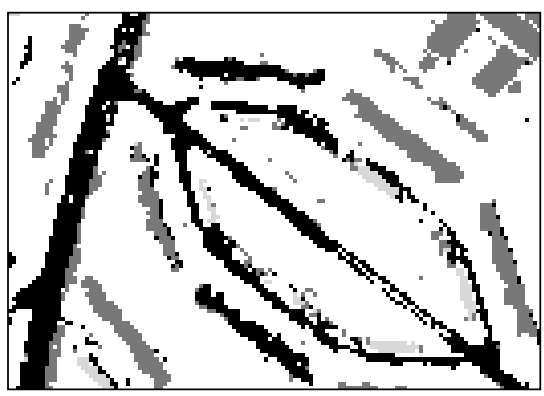

(d) CHAFFEE man-made surface/roofing.

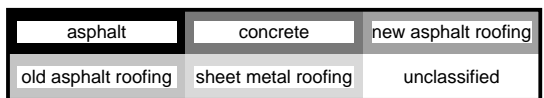

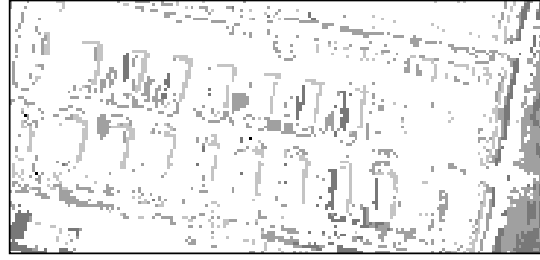

(b) RADT9 bare earth/shadow.

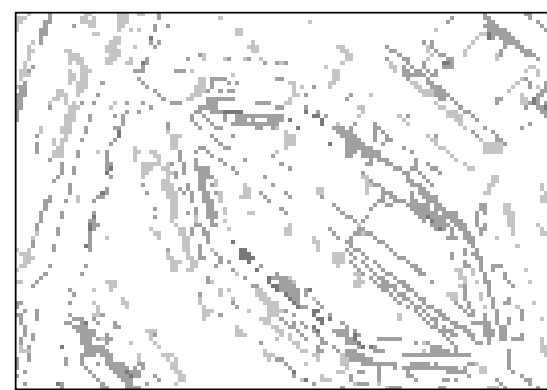

(e) CHAFFEE bare earth/shadow.

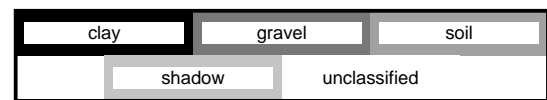

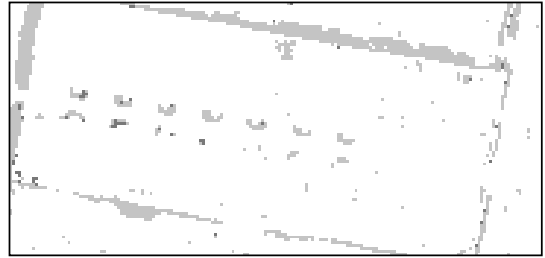

(c) RADT9 vegetation/water.

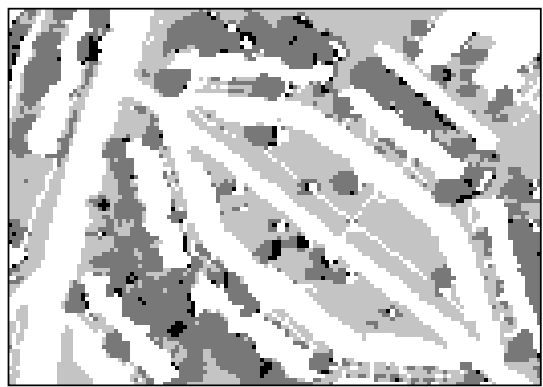

(f) CHAFFEE vegetation/water.

\begin{tabular}{|c|c|c|}
\hline coniferous tree & deciduous tree & deep water \\
\hline grass & turbid water & unclassified \\
\hline
\end{tabular}

Fig. 2: Test area subsection surface material classification.

TABLE II: Fine to coarse class grouping.

\begin{tabular}{||c||c||}
\hline $\begin{array}{c}\text { Coarse } \\
\text { Surface Material }\end{array}$ & $\begin{array}{c}\text { Fine } \\
\text { Surface Material }\end{array}$ \\
\hline \hline man-made surface & $\begin{array}{c}\text { asphalt } \\
\text { concrete }\end{array}$ \\
\hline bare earth & $\begin{array}{c}\text { soil } \\
\text { clay } \\
\text { gravel }\end{array}$ \\
\hline vegetation & $\begin{array}{c}\text { grass } \\
\text { deciduous tree } \\
\text { coniferous tree }\end{array}$ \\
\hline water & $\begin{array}{c}\text { deep water } \\
\text { turbid water }\end{array}$ \\
\hline man-made roofing & $\begin{array}{c}\text { new asphalt roofing } \\
\text { old asphalt roofing } \\
\text { sheet metal roofing }\end{array}$ \\
\hline shadow & shadow \\
\hline
\end{tabular}

made or natural surface features. Table V and Table VI display the error matrices for the coarse classification for each of the test areas. Coarse classification accuracies range from $72.8 \%$ (CHAFFEE) to $75.0 \%$ (RADT9). For RADT9, the majority of the error $(10.4 \%)$ involves man-made surface and bare earth confusions while CHAFFEE's dominant error $(8.1 \%)$ is confusion between shadow and vegetation. These coarse surface material confusions have similar trends that were seen in the earlier fine material classification.

We are currently working on the utilization of HYDICE's high spectral resolution for spectral similarity and linear mixture analysis with ground measured surface material reflectance curves.
TABLE III: RADT9 top 5 confusion pairs

\begin{tabular}{|c|c|c|c||}
\hline $\begin{array}{c}\text { Ground Truth } \\
\text { Class }\end{array}$ & $\begin{array}{c}\text { Classification } \\
\text { Class }\end{array}$ & $\begin{array}{c}\text { Number } \\
\text { Confused }\end{array}$ & $\begin{array}{c}\text { Error } \\
\text { Percentage }\end{array}$ \\
\hline \hline concrete & asphalt & 7074 & $10.3 \%$ \\
\hline soil & gravel & 2756 & $4.0 \%$ \\
\hline grass & soil & 2233 & $3.3 \%$ \\
\hline asphalt & soil & 1703 & $2.5 \%$ \\
\hline concrete & soil & 1558 & $2.3 \%$ \\
\hline \hline Total & & 15324 & $22.4 \%$ \\
\hline
\end{tabular}

TABLE IV: CHAFFEE top 5 confusion pairs

\begin{tabular}{||c|c|c|c||}
\hline $\begin{array}{c}\text { Ground Truth } \\
\text { Class }\end{array}$ & $\begin{array}{c}\text { Classification } \\
\text { Class }\end{array}$ & $\begin{array}{c}\text { Number } \\
\text { Confused }\end{array}$ & $\begin{array}{c}\text { Error } \\
\text { Percentage }\end{array}$ \\
\hline \hline shadow & deciduous tree & 3571 & $4.8 \%$ \\
\hline deciduous tree & grass & 3447 & $4.7 \%$ \\
\hline $\begin{array}{c}\text { old asphalt } \\
\text { roofing }\end{array}$ & concrete & 2522 & $3.4 \%$ \\
\hline grass & deciduous tree & 2084 & $2.8 \%$ \\
\hline asphalt & soil & 1647 & $2.2 \%$ \\
\hline \hline Total & & 13271 & $17.9 \%$ \\
\hline
\end{tabular}

\section{CONCLUSIONS}

With the acquisition of a high spatial resolution HYDICE image set, an opportunity exists to exploit the spectral information from hyperspectral imagery to aid urban scene analysis for cartographic feature extraction. Radiometric effects from changing solar illumination and atmospheric conditions must 
TABLE V: RADT9 coarse classification error matrix.

\begin{tabular}{|c|c|c|c|c|c|c|c|c|}
\hline \multirow[b]{2}{*}{ TEST } & \multicolumn{8}{|c|}{ REFERENCE } \\
\hline & $\begin{array}{l}\text { man-made } \\
\text { surface }\end{array}$ & $\begin{array}{l}\text { bare } \\
\text { earth }\end{array}$ & vegetation & water & $\begin{array}{l}\text { man-made } \\
\text { roofing }\end{array}$ & shadow & $\begin{array}{l}\text { Row } \\
\text { Total }\end{array}$ & $\begin{array}{c}\text { Commission } \\
\text { Error }\end{array}$ \\
\hline man-made surface & 26677 & 1973 & 1509 & 0 & 1477 & 608 & 32244 & 17.3 \\
\hline bare earth & 5129 & 7299 & 2444 & 0 & 254 & 58 & 15184 & 51.9 \\
\hline vegetation & 377 & 822 & 14666 & 0 & 117 & 149 & 16131 & 9.1 \\
\hline water & 0 & 0 & 0 & 0 & 0 & 0 & 0 & $*$ \\
\hline man-made roofing & 671 & 182 & 285 & 0 & 1598 & 367 & 3103 & 48.5 \\
\hline shadow & 130 & 33 & 425 & 0 & 79 & 1153 & 1820 & 36.6 \\
\hline Column Total & 32984 & 10309 & 19329 & 0 & 3525 & 2335 & 68482 & \\
\hline \multirow[t]{2}{*}{ Omission Error } & 17.3 & 51.9 & 9.1 & $*$ & 48.5 & 36.6 & & Percent \\
\hline & \multicolumn{8}{|c|}{ Overall Accuracy $=51393 / 68482=75.0 \%$} \\
\hline
\end{tabular}

TABLE VI: CHAFFEE coarse classification error matrix.

\begin{tabular}{|c|c|c|c|c|c|c|c|c|}
\hline \multirow[b]{2}{*}{ TEST } & \multicolumn{8}{|c|}{ REFERENCE } \\
\hline & $\begin{array}{c}\text { man-made } \\
\text { surface }\end{array}$ & $\begin{array}{l}\text { bare } \\
\text { earth }\end{array}$ & vegetation & water & $\begin{array}{c}\text { man-made } \\
\text { roofing }\end{array}$ & shadow & $\begin{array}{l}\text { Row } \\
\text { Total }\end{array}$ & $\begin{array}{c}\text { Commission } \\
\text { Error }\end{array}$ \\
\hline man-made surface & 6693 & 0 & 1773 & 0 & 3809 & 921 & 13196 & 49.3 \\
\hline bare earth & 2213 & 0 & 1891 & 0 & 684 & 548 & 5336 & 100.0 \\
\hline vegetation & 472 & 0 & 43949 & 0 & 644 & 5986 & 51051 & 13.9 \\
\hline water & 0 & 0 & 0 & 0 & 0 & 0 & 0 & $*$ \\
\hline man-made roofing & 80 & 0 & 92 & 0 & 564 & 116 & 852 & 33.8 \\
\hline shadow & 77 & 0 & 496 & 0 & 318 & 2527 & 3418 & 26.1 \\
\hline Column Total & 9535 & 0 & 48201 & 0 & 6019 & 10098 & 73853 & \\
\hline \multirow[t]{2}{*}{ Omission Error } & 49.3 & $*$ & 13.9 & $*$ & 33.8 & 26.1 & & Percent \\
\hline & \multicolumn{8}{|c|}{ Overall Accuracy $=53733 / 73853=72.8 \%$} \\
\hline
\end{tabular}

be accounted for in order to support comparison of surface material properties across HYDICE flightlines. To utilize the surface material information to its full potential, accurate geopositioning of HYDICE imagery is crucial for fusing surface material information with stereo and monocular cues.

\section{ACKNOWLEDGMENTS}

We would like to acknowledge the support of Mr. George Lukes, DARPA Program Manager, Synthetic Environments, and Mr. Doug Caldwell, USATEC, in this data collection and exploitation effort.

We would also like to thank Mark Anderson, Dave Pope, John Colwell, Bill Aldrich, and Mary Kappus (HYDICE program office), Joe Deaver (HYDICE flight operations group), Hugh Kieffer (USGS), Bob Basedow (Hughes Danbury), Kelley McVey and Blake Arnold (ERIM), Dave Kelch, Dave Fatora, Brett Sink and Phil Lind (MTL Systems), and MG (Ret) Ben Harrison (U.S Army, Fort Hood).

\section{REFERENCES}

[1] S. J. Ford and D. M. McKeown, Jr., "Utilization of multispectral imagery for cartographic feature extraction," in DARPA IUW, (San Diego, CA), pp. 805-820, DARPA, Morgan Kaufmann, Jan. 1992.

[2] S. J. Ford and D. M. McKeown, Jr., "Information fusion of multispectral imagery for cartographic feature extraction," in Int. Archives of Photogrammetry and Remote Sensing: Interpretation of Photographic and Remote Sensing Data, vol. XVII, B7, (DC), 2-14 Aug. 1992. XVIIth Congress, Commission VII.

[3] S. Ford and D. McKeown, "Performance evaluation of multispectral analysis for surface material classification,' in Proc. Int. Geosci. Remote Sensing, IGARSS'94, (Pasadena, CA), pp. 2112-2116, 8-12 Aug. 1994.

[4] S. J. Ford, D. Kalp, J. C. McGlone, and D. M. McKeown, Jr., "Preliminary results on the analysis of HYDICE data for information fusion in cartographic feature extraction," in Proc. SPIE: Integrating Photogrammetric Techniques with Scene Analysis and Machine Vision III, vol. 3072, pp. 67-86, Apr. 1997. Also available as Technical Report CMU-CS-97-116, School of Computer Science, Carnegie Mellon University, Pittsburgh, PA 15213. 